J. Dairy Sci. 97:6623-6623

http://dx.doi.org/10.3168/jds.2014-97-10-6623

(c) American Dairy Science Association ${ }^{\circledR}, 2014$.

\title{
Erratum to "Short communication: Heat resistance of Escherichia coli strains in raw milk at different subpasteurization conditions" (J. Dairy Sci. 96:3543-3546)
}

\section{S. Peng, J. Hummerjohann, R. Stephan, and P. Hammer}

During ongoing experiments with the pilot plant used for heat inactivation of the Escherichia coli strain, we recognized that the plate apparatus of the heating section of the plant contributed considerably to the total holding time. To account for this, we calculated an equivalent holding time, as follows. Based on the temperatures at the inlet and outlet of the plate apparatus, the flow rate, the heating menstruum (water in this case), and the milk, a temperature curve for the heating section was derived. From this curve, we determined the point at which the inactivating temperature for the test organism was reached and calculated the residual time until the outlet of the heater was passed. The equivalent holding times to be added to the existing holding times of 25,20 , and $15 \mathrm{~s}$ were 10,5 , and $1.5 \mathrm{~s}$, respectively. Based on the expanded holding times, the $D$ - and $z$-values (Table 1 ; page 3544 ) were recalculated and the revised values are shown in bold. The changes in $D$ - and $z$-values do not affect the conclusions of the study.

The authors regret the error.

\section{REFERENCE}

Peng, S., J. Hummerjohann, R. Stephan, and P. Hammer. 2013. Short communication: Heat resistance of Escherichia coli strains in raw milk at different subpasteurization conditions. J. Dairy Sci. 96(6):3543-3546.

Table 1. D-values (s) and $z$-values $\left({ }^{\circ} \mathrm{C}\right)$ of 9 Escherichia coli strains ${ }^{1}$

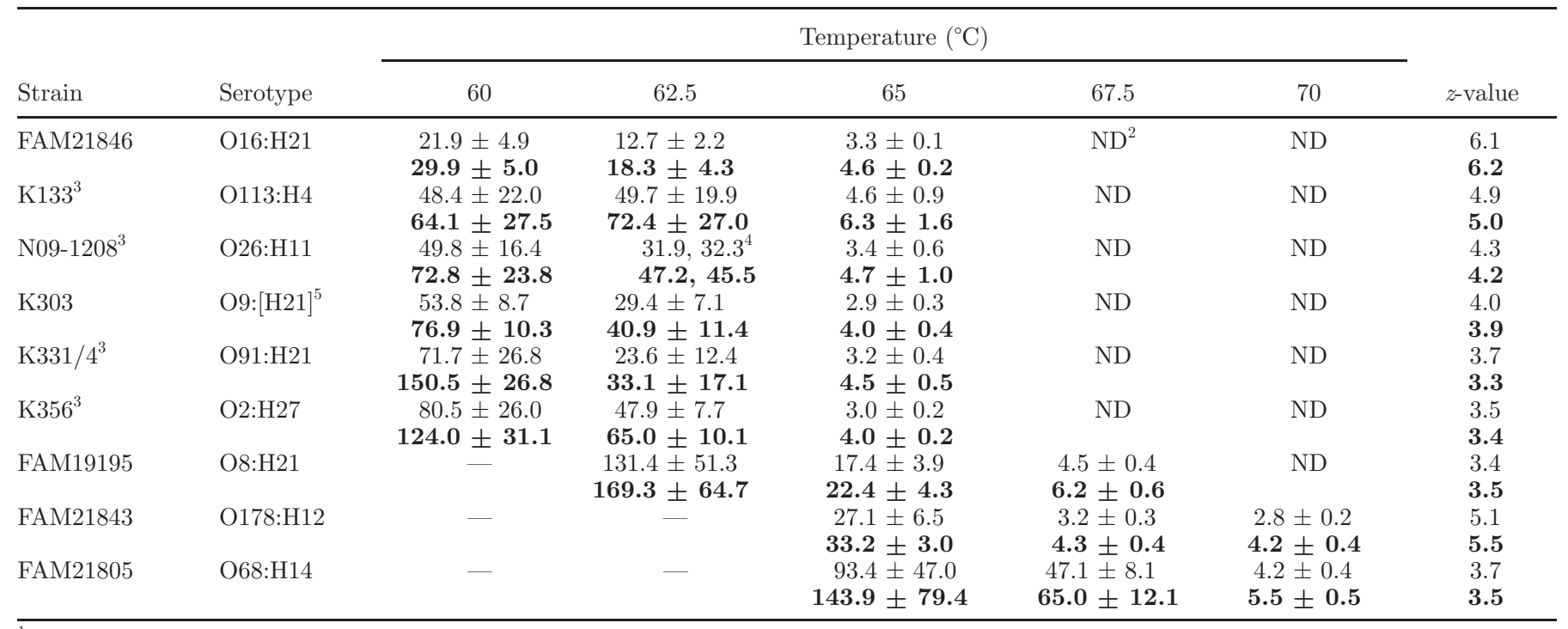

${ }^{1}$ Mean \pm SD of 3 experiments per strain and temperature for calculation of $D$-values (time needed at a certain temperature for $1 \log _{10}$ reduction of the bacterial count); the $z$-value (temperature needed for $1 \log _{10}$ reduction of the $D$-value) was calculated from the average $D$-values. The values in bold for each strain represent the values adjusted for the revised equivalent holding times.

${ }^{2}$ Not determined.

${ }^{3}$ Shiga toxin-producing E. coli strain.

${ }^{4}$ Only 2 experiments due to low coefficient of determination.

${ }^{5}$ Phenotypically nonmotile.

${ }^{6}$ No significant reduction observed (reduction $\leq 0.25 \log _{10}$ ). 